\title{
НАЧАЛО ДЕЯТЕЛЬНОСТИ СОВЕТСКОГО ПОЛПРЕДСТВА В БЕРЛИНЕ В 1918 Г.: ЭКОНОМИЧЕСКИЙ АСПЕКТ
}

\section{THE BEGINNING ACTIVITY OF THE SOVIET EMBASSY IN BERLIN IN 1918: THE ECONOMIC ASPECT}

\section{A. Vatlin}

Summary: The article examines the initial period of Soviet-German relations associated with the appearance in Berlin in April 1918 of the Soviet diplomatic mission headed by A.A. Ioffe. An important area of activity of the plenipotentiary was the implementation of the Brest Treaty, including its financial and economic component. The article analyzes the first attempts to establish trade relations, solve the problem of mutual claims and other aspects of the activities of the plenipotentiary.

Keywords: Peace of Brest, Bolsheviks, Soviet embassy, A.A. Ioffe, L.B. Krasin, German Ministry of Foreign Affairs, financial policy.

\author{
Ватлин Александр Юрьевич \\ Д.и.н., профессор, Московский государственный \\ университет им. М.В. Ломоносова \\ vatlin_alex@mail.ru
}

Аннотация: В статье рассматривается начальный период советско-германских отношений, связанный с появлением в Берлине в апреле 1918 г. советского дипломатического представительства во главе с А.А. Иоффе. Важной сферой деятельности полпредства была имплементация Брестского договора, В том числе и его финансово-экономической составляющей. В статье проанализированы первые попытки налаживания торговых отношений, решения проблемы взаимных претензий и иные аспекты деятельности полпредства.

Ключевые слова: Брестский мир, большевики, советское полпредство, А.А. Иоффе, Л.Б. Красин, Министерство иностранных дел Германии, финансовая политика.
3 аключение Брестского мирного договора между Советской Россией и Германской империей подразумевало восстановление дипломатических отношений между странами. Верховное главнокомандование Германии высказалось против того, чтобы посланцы большевиков начали свою работу в Берлине. Сам факт их присутствия, не говоря уже о возможной пропаганде революционных идей, являл собой серьезную угрозу стабильности Германского рейха. Предложенный военными вариант, согласно которому оба посольства находились бы на российской территории, оккупированной немецкими войсками, не нашел поддержки в МИДе. Там были уверены в том, что «режим максималистов», как называли партию Ленина, не продержится долго, а для правового закрепления итогов победоносной войны на Востоке дипломатам был необходим прямой канал связи с Москвой.

В деятельности советского дипломатического представительства, работавшего в Берлине с конца апреля по начало ноября 1918 г., нашел свое отражение поиск большевиками нового содержания и методов внешней политики. Провозгласив сразу же после прихода к власти отказ от тайной дипломатии и кабальных соглашений, сделав ставку на продвижение вперед мировой социалистической революции, они были вынуждены смириться с тем, что «правила игры» в сфере внешней политики продолжали диктоваться империалистическими державами.

На пост советского полпреда в Германии был назна- чен А.А. Иоффе, который на протяжении всей своей дореволюционной биографии являлся меньшевиком, но после Октябрьского переворота перешел на позиции большевизма и не без оснований считал себя одним из ближайших соратников Ленина и Троцкого. Его назначение на пост дипломатического представителя Советской России в Германии можно считать закономерным уже потому, что он получил высшее образование в Вене и Берлине и блестяще владел немецким языком. Германским властям пришлось согласиться с этой кандидатурой, хотя наверняка они были осведомлены о связях будущего полпреда в период его эмиграции с германскими левыми социалистами.

Отправляясь в Германию, Иоффе, еще недавно один из «левых коммунистов» и противник заключения Брестского мира, реализовал установку В.И. Ленина, которую получил при отъезде: всеми средствами обеспечивать мирную «передышку» для Советской России, «удерживать» натиск на нее, выражавшийся в продолжавшейся агрессии германской армии на Востоке, и в то же время вести нелегальную революционную пропаганду среди своих немецких единомышленников [6, с. 35]. В меньшей степени известна финансово-экономическая деятельность полпредства, основными направлениями которой была имплементация Дополнительного договора, подписанного в Бресте [4, с. 166-183], а также налаживание торговых отношений между странами в условиях продолжающейся мировой войны. Особое значение имел вопрос о разделе имущества между наследниками бывшей Российской империи. Сразу же по прибытии в 
Берлин Иоффе столкнулся с тем, что свои претензии на историческое здание российского посольства заявили и украинские дипломаты.

Серьезную проблему для эффективной работы полпредства представляло собой отсутствие надежной связи с Москвой. Политические доклады отправлялись курьерами, радиограммы, пересылаемые через сеть радиостанций, доходили до получателя только через несколько дней, аппарат Юза начал действовать только в начале июня, причем переговоры по прямому проводу постоянно прерывались обрывами и неполадками на линии. Не менее важным был и кадровый голод, о котором Иоффе неоднократно сообщал в Москву, требуя присылки толковых экспертов и помощников, особенно в финансовых вопросах.

О неразберихе в аппарате полпредства ярко свидетельствуют мемуары его первого секретаря Г.А. Соломона, ставшего впоследствии «невозвращенцем»: «в посольстве, благодаря набранному с бора да с сосенки штату, царит крайняя запущенность в делопроизводстве, в отчетности, в хозяйстве,... хотя служащие и неопытны, но самомнение у них громадное и амбиций хоть отбавляй» [11, с. 32]. В этих условиях полпреду, который и сам не имел дипломатического опыта, трудно было на равных вести переговоры с опытными германскими дипломатами во главе со статс-секретарем Р. Кюльманом и руководителем правового отдела МИД Й. Криге. Тем не менее, в крайне неблагоприятных условиях Иоффе сумел наладить работу полпредства, найти нужный тон в отношениях с немецкими партнерами. Незаменимую помощь ему оказал Л.Б. Красин, прибывший из Стокгольма 20 мая 1918 г. вначале на несколько дней, но затем оставшийся до августа. Он фактически превратился в руководителя экономического отдела полпредства и его главного финансового эксперта.

До революции Красин работал на фирме «Сименс», и знакомство с ее высшими менеджерами открыло ему двери в кабинеты высшей власти Германии. Так, уже в начале июня он был принят самим генералом Э. Люденддорфом, который фактически возглавлял Генеральный штаб Верховного главнокомандования. Тот в жестком тоне высказал свои претензии к советскому правительству, однако признал заинтересованность в налаживании торговых отношений: «Процветет ли у вас национализация или вы возвратитесь к частной собственности, это нам более или менее безразлично, главное для нас иметь возможность получить от вас нужные нам сырьё, материалы и прочее» [3, с. 36-37].

По итогам встречи Красин вынес мнение, что «известный компромисс... является сейчас с Россией желательным и для военной партии», «немцы хотят попробовать завязать с нами деловые отношения и в меру успешности этой политики оставят нас более или менее в покое», писал он Ленину сразу после переговоров с Людендорфом [3, с. 37]. Такой прогноз означал, что налаживание торговли с Германией приобретает для Советской России жизненно важное значение, ибо «в случае резкого отказа с нашей стороны от такой работы, репрессии могут быть применены в самом близком будущем», и будут означать прежде всего новый виток германской агрессии. Впоследствии именно Красин добился подписания единственного договора о товарообмене между Россией и Германией до завершения Первой мировой войны в нем шла речь о поставке 100 тыс. тонн немецкого угля в обмен на российское сырье, которого так не хватало для германской промышленности - медь и резину.

Красин обращался к Ленину с просьбой взять под личный контроль реализацию данного соглашения, считая ее одним из первых примеров государственной монополии на внешнюю торговлю: «Я считаю нужным просить Вас произвести специальный нажим, так как от успеха первого опыта зависит не только снабжение Питера углем на всю зиму, но и вся наша политика здесь получит прочную основу, если немцы увидят, что мы относимся к товарообороту серьезно и не только хотим, но и умеем за него взяться» [9, л. 40]. 4 августа 1918 г. первый пароход с углем, зафрахтованный фирмой Г. Стиннеса, отправился из Гамбурга в Петроград. Оставив Красину подготовку торговых соглашений, Иоффе взял на себя контакты с крупнейшими немецкими финансистами, которые, по его словам, «как мухи облепили» полпредство. Они рассчитывали на роль посредников при реализации тех статей брестских соглашений, которые подразумевали компенсацию потерь немецких предпринимателей в Советской России и сулили банкирам немалые барыши.

Полпред разделял мнение Красина, что огромный ущерб позитивному развитию отношений двух стран наносят карикатурные образы новой власти в России: «нужно считаться с тем, что среди влиятельных кругов Германии существует предвзятое убеждение, что большевики, по мнению одних, идеалисты и фантазеры, по мнению других - грабители и разбойники, но что во всяком случае с ними никакой реальной политики вести невозможно, их власть висит на волоске и поэтому нужно самим брать то, что возможно взять» [1, д. 987, л. 25-26]. Единственный способ в корне подорвать подобные стереотипы - доказать, что и большевики могут наладить учет и контроль, вести цивилизованную внешнюю торговлю.

В немецкой историографии подробно анализируются первые попытки установить торговые контакты между двумя странами, несмотря на сохранявшееся состояние «ни мира ни войны ни мира» и дезорганизацию 
советского хозяйственного аппарата. Винфрид Баумгарт, один из лучших знатоков германской «остполитик» 1918 г., в своей классической монографии справедливо противопоставляет агрессивной и бесплодной политике радикал-большевиков вроде Карла Радека «метод Иоффе, который привел к большему успеху и состоял в том, чтобы обернуть в свою пользу интерес германских предпринимательских кругов к возрождению торговли с Россией [13, с. 277]. Полпред предложил созвать в Берлине особую финансовую комиссию и сам предложил план ее работы, который включал вопросы о компенсации за содержание военнопленных, выплату купонов по акциям и займам, держателями которых являлись германские граждане, утверждение механизма подачи претензий за утраченные ими активы предприятий, находившихся на территории России.

С немецкой стороны в комиссию вошли руководители крупнейших банков страны и Имперского казначейства, однако из России так и не прибыли запрошенные Иоффе финансовые эксперты. Сказывалось недоверие к «буржуазным спецам» и страх перед их возможным саботажем. Как и в военной сфере, в экономике Ленин делал ставку на людей, которые пользовались его личным доверием: «Надо послать только архинадежных большевиков, пусть хуже стратеги, но надежные люди и умные» [8, с. 248]. В результате в Берлин отправились Ю. Ларин и Г.Я. Сокольников, которые не обладали должным опытом ведения финансовых переговоров.

Во время переговоров с руководством германского МИДа Иоффе заявил, что «вопрос о наших долгах находится в полной непосредственной зависимости от результатов работ политической комиссии», т.е. от урегулирования ключевых моментов в отношениях двух стран, и прежде всего - приостановки германского наступления вглубь России [10, л. 1-2]. Он тщательно собирал все материалы немецкой прессы, в которых указывались масштабы изъятия имущества на территории, оккупированной Германией. При этом Иоффе требовал от Ленина и наркома иностранных дел Г.В. Чичерина, «чтобы Вы мне представили такие цифры: какова стоимость нашего флота, захваченного немцами, на какую, приблизительно, сумму они могли награбить в Крыму и т.п.» [10, л. 1]. С точки зрения Иоффе возможность получать из России сырье и товары, необходимые как для продолжения войны, так и для преодоления нарастающего голода, имела для берлинских властей не только экономическое, но и внутриполитическое значение: укрепив торговые отношения с Германий, «мы сможем потребовать еще большего из того, за что раньше торговались. Ибо все время в наших руках будет величайший наш козырь, возможность лишить германских империалистов их основной силы: веры народа в их миролюбие, разрушить иллюзию мира на Востоке, ибо никто не поверит, что мы желали войны» [1, д. 987, л.11].

Полпред отдавал себе отчет в том, что данная иллюзия, которую пестовали правящие круги и официозная пресса Германии, тормозила нарастание революционных настроений в социальных низах, откладывая на будущее перспективу пролетарской революции в стране, однако был вынужден наступить на горло собственной песне, выбрав из двух перспектив наиболее реалистичную - разработку договорной основы для деловых отношений двух стран. «Германская революция опоздала, вместо политики ставки на революцию у нас теперь политика ставки на передышку. Передышку этот договор дает, хотя, быть может, очень краткосрочную. Поэтому его нужно принимать и принимать немедленно, ибо затяжка столь же вредна, как и отклонение. Большего добиться, по-моему, нельзя, и я полагаю, что не мог бы добиться никто» [1, д. 988, л. 108-109].

Иоффе не только решал в Берлине оперативные вопросы, связанные с работой финансовой комиссии, но и пытался воздействовать на стратегию экономической политики, которая вырабатывалась в Москве. Он крайне жестко отреагировал на передачу открытым текстом концепции переговоров, в которой Советская Россия соглашалась с появлением в стране немецких концессий. «Не говоря уже о том, что просто преступлением было кричать о ней на весь мир, мне думается, что и по существу тут многое неправильно: концессии, несомненно, нам весьма невыгодны, ибо при концессиях, какие бы оговорки мы не вводили, мы рискуем похоронить и 8-часовой рабочий день, и высокую заработную плату, т. е. восстановить против себя пролетариат и остаться без армии. Гораздо выгоднее, по-моему, передача на откупа наших акцизов или монополий» [1, д. 987, л. 18-19].

В своих донесениях полпред корректировал левацкие трактовки экономической системы Германии как сферы господства финансового капитала, подчеркивая, что магнаты тяжелой индустрии действуют вполне независимо от банков, опираясь на тесные контакты с военным руководством страны. Такой подход не нашел поддержки в Москве, поскольку отходил от канонов ленинского понимания империализма, хотя он в большей степени соответствовал реальному положению дел. Сказывалось то, что Иоффе находился буквально на передовой и воочию видел то, о чем сообщал руководителям РКП(б): «немецкие финансисты не хотят войны с нами, они не хотят иметь врага в России, они скрепя сердце принимают все политические ошибки военных, ибо те нужны им еще на Западе, но они хотят уже получить от России свой фунт мяса» $[9$, л. 3]. Хотя в Москве критиковали излишний «оптимизм» советского полпреда в Берлине, Ленин признавал, что его практическая деятельность показывает, «насколько серьезно мы хотим 
деловых экономических отношений... Политику Вашу, особенно подробно в письмах т. Иоффе изложенную, я вполне одобряю» [7, с. 79-80].

В переписке с Лениным Иоффе выступил против эмиссии советских денежных знаков, ссылаясь на то, что они не будут приняты населением, а германские военные власти на оккупированной территории начнут игру на понижение стоимости царских денег, чтобы таким образом расплатиться за украинский хлеб. В ходе переговоров с немецкими финансистами он согласился на паушальную оценку взаимных претензий, что было невыгодным для России, но неизбежным шагом, так как отражало ее слабость перед лицом возможного расширения германской агрессии. Данный подход, который немецкая сторона отстаивала уже в ходе брестских переговоров, диктовался не только стремлением добиться максимального удовлетворения частных интересов. Речь шла о попытке заведомо невыполнимой контрибуцией зафиксировать финансовую зависимость Советской России от Германии, чтобы впоследствии добиваться от нее масштабных торгово-экономических уступок.

Чичерин в письме Иоффе высказывал оправданные сомнения в том, следует ли России соглашаться с таким подходом: «Относительно паушальной суммы я должен заметить, что в случае благоприятной для нас перемены мировой ситуации при отсутствии паушальной выплаты мы сможем перестать платить, а при паушальной выплате окажется, что мы все уже выложили» [1, д. 992, л. 65]. Летом 1918 г. трудно было предвидеть быстрый крах Германской империи, который менее чем через полгода позволил России денонсировать Брестский мир и отказаться от выплаты наложенной на нее контрибуции.

В начале июля 1918 г. Иоффе и Красин направили в Москву отчет о первых итогах своей работы по установлению торговых связей между двумя странами. О ее масштабе свидетельствовало уже простое перечисление немецких партнеров, с которыми в течение двух месяцев были установлены деловые контакты: «Переговоры велись с представителями печати и так называемого общественного мнения самых разнообразных кругов, с представителями различных партий рейхстага от самых левых до национал-либералов, с купцами и промышленниками всевозможных отраслей, представителями частных банков, государственного банка и министерства финансов, со статс-секретарем по делам промышленности и торговли, различными чиновниками министерства иностранных дел, и наконец, с представителями военного министерства, начиная от лиц, заведующих различными военно-промышленными обществами, закупкой сырья и проч., и кончая наиболее видными и влиятельными представителями так называемой военной партии» $[2$, л. 47].
Авторы отчета, который был передан также и немецкой стороне, справедливо отмечали, что главным препятствием к восстановлению торговых отношений между двумя странами является необъявленная война Германии против России, в ходе которой она «занимает все новые и новые области, незаконно присваивает себе миллиардные ценности, принадлежащие российской казне и российским гражданам, и отрезает Великороссию последовательно от важнейших областей снабжения хлебом, рудой, металлом, каменным углем и нефтью» $[2$, л. 48].

Но даже в таких условиях берлинское представительство продолжало убеждать немецкие деловые круги и общественное мнение Германии в том, что «путем насильственного захвата Германия не получит от России тех товаров и сырья, в которых она нуждается», справедливо указывая на судьбу Украины, оккупация которой не привела к выкачиванию еехлебных ресурсов [2, л. 48-49]. Иоффе и Красин предлагали иные, взаимовыгодные пути налаживания деловых связей между двумя странами, подразумевавшие «прекращение враждебных действий, ... возмещение убытков и ущербов, восстановление свободного судоходства по Черному и Балтийскому морям, беспрепятственное разрешение сношений и обращения товаров между Великороссией и оккупированными ее частями» $[2$, л. 49-50]. Этим они руководствовались и в своей практической работе в Берлине, неизменно подчеркивая, что и после Бреста Россия не стала союзником и сателлитом Германии, а превратилась в нейтральную страну, которая сохраняет за собой право самостоятельного налаживания экономических связей со скандинавскими странами и США.

Высшей точкой политических отношений между Россией и Германией на заключительном этапе Первой мировой войны стало заключение Добавочного договора 27 августа 1918 г. Его составной частью являлось финансовое соглашение, в котором был зафиксирован общий размер выплат, наложенных на Советскую Россию «для вознаграждения потерпевших от русских мероприятий германцев» - 6 млрд. немецких марок [4, с. 446-448]. Механизм расчета таких компенсаций был согласован в специальных тайных нотах, которыми стороны обменялись в день подписания Добавочного договора. В них специально оговаривалось, что «финансовым соглашением не затрагивается право германских акционеров национализированных в России предприятий на причитающиеся им за период до национализации дивиденды» $[14$, л. 101].

По сути дела, августовский договор, несмотря на тактические уступки, которые удалось «выторговать» Иоффе и о которых он регулярно сообщал в Москву [9, л. 54-58, 89-90], являл собой кодификацию империалисти- 
ческой политики германских властей. По точному определению Фрица Фишера, книга которого в начале 1960-х гг. вызвала острую дискуссию в международной историографии, «договор, заключенный на таких основаниях, являл собой закономерный этап в старой аннексионистской линии в вопросах военных целей, частью реализованных еще в Бресте: это была современная форма экономической вассальной зависимости» [12, с. 599].

Несмотря на скоротечный финал советско-германских отношений в начале ноября 1918 г., когда полпредство Иоффе было выслано из Берлина буквально за три дня до краха империи Гогенцоллернов, их экономическую составляющую вряд ли можно считать бессодержательным эпизодом. В ходе контактов с немецкими политиками и предпринимателями были установлены связи, которые будут востребованы впоследствии в ходе реализации Рапалльского договора 1922 г. Достаточно сказать, что одним из главных «ходатаев» по русским вопросам летом 1918 г. являлся хорошо знакомый Иоффе и Красину Густав Штреземан - на тот момент один из лидеров Национал-либеральной партии, а в будущем канцлер Веймарской республики, лауреат Нобелевской премии мира и сторонник интеграции Германии в послевоенную Европу [5, с. 75-82]. Налаживание деловых связей (при всей скромности их масштабов) между двумя странами в чрезвычайных условиях Первой мировой войны и Гражданской войны в России стало первым примером позитивного взаимодействия государств с противоположным общественным строем, за которым последуют другие эпизоды в истории мировой экономики XX века.

\section{ЛИТЕРАТУРА}

1. Архив внешней политики Российской Федерации. Ф. 4. Оп. 13. П. 70.

2. Архив внешней политики Российской Федерации. Ф. 82. Оп. 1. П. 24. Д. 100.

3. Ватлин А.Ю. «В прочность положения большевиков я не очень-то верю» // Воронцово поле. Вестник фонда «История отечества». 2020. № 4. С. 32-37.

4. Документы внешней политики СССР. Т. 1. М.: Политиздат, 1957. 770 с.

5. Евдокимова Т.В. Рейхсминистры веймарской Германии: между властью и безвластием. Волгоград: Изд-во Волгоградского государственного социальнопедагогического университета, 2020. 462 с.

6. Иоффе А.А. Германская революция и Российское посольство // Вестник жизни. 1919. № 5. С. 35-46.

7. Ленин В.И. Полное собрание сочинений. Т. 50. М.: Политиздат, 1982. 623 с.

8. Ленин В.И. Неизвестные документы. 1891-1922. М.: РОССПЭН, 1999. 670 с.

9. Российский государственный архив социально-политической истории. Ф. 159. Оп. 2. Д. 33.

10. Российский государственный архив социально-политической истории. Ф. 2. Оп. 1. Д. 5994.

11. Соломон Г.А. Среди красных вождей. Лично пережитое и виденное на советской службе. М.: Центрполиграф, 2015. 509 с.

12. Фишер Ф. Рывок к мировому господству. Политика военных целей кайзеровской Германии в 1914-1918 гг. Пер. с нем. Л.В. Ланника. М.: РОССПЭН, 2017. 799 c.

13. Baumgart W. Deutsche Ostpolitik 1918: von Brest-Litowsk bis zum Ende des Ersten Weltkrieges. Wien; München: Oldenbourg Verlag, 1966. 462 S.

14. Politisches Archiv des Auswärtigen Amtes. RZ 201/2012.

(c) Ватлин Александр Юрьевич (vatlin_alex@mail.ru).

Журнал «Современная наука: актуальные проблемы теории и практики» 